\title{
Validação de novo amostrador de furos de desmonte para fins de reconciliação
}

\author{
Validation of a new blasthole sampler \\ for reconciliation purposes
}

\begin{abstract}
Ana Carolina Chieregati
ana.chieregati@gmail.com

Bruno Brunetti Frontini

Estudante de Engenharia de Minas,

Escola Politécnica da USP

bruno.frontini@gmail.com

\section{Geólogo, \\ Yamana Gold}

Daniel Bortowski Carvalho

daniel.bortowski@yamana.com
\end{abstract}

Profa. Dra., Departamento de Engenharia de

Minas e de Petróleo, Escola Politécnica da USP

\section{Francis F. Pitard}

Consultor,

Francis Pitard Sampling Consultants

fpsc@aol.com

Kim H. Esbensen

Prof. Dr., Geólogo, GEUS,

ACABS Research Group,

Aalborg University

ke@geus.dk

\section{Resumo}

As operações mineiras, em todo o mundo, fazem uso extensivo da amostragem de furos de desmonte para o planejamento de curto prazo, o que apresenta duas vantagens indiscutíveis: (1) o espaçamento entre os furos é pequeno, fornecendo uma alta densidade de amostragem por tonelada de minério e (2) não há custos adicionais, já que os furos devem ser perfurados de qualquer maneira. Entretanto a precisão da amostragem de furos de desmonte é, normalmente, baixa e o enviesamento causado pela segregação de densidade e tamanho de partículas é um problema ainda mais sério, que prejudica a representatividade das amostras geradas. Uma das principais causas desse enviesamento é a perda de finos, que pode levar a uma sub ou superestimativa do teor do minério, dependendo do tipo de minério e da ganga. O presente trabalho valida um novo equipamento de amostragem, projetado para reduzir a perda de finos e, assim, aumentar a acurácia da amostragem de furos de desmonte de pequeno diâmetro. Os resultados iniciais mostram uma melhoria significativa na estimativa do teor de ouro e a minimização da perda de finos.

Palavras-chave: Amostragem, reconciliação, ouro, amostrador setorial estacionário, amostragem de furos de desmonte.

\begin{abstract}
Mining operations around the world make extensive use of blasthole sampling for short-term planning, which has two undisputed advantages: (1) blastholes are closely spaced providing relatively high sampling density per ton, and (2) there is no additional cost since the blastholes must be drilled anyway. However, blasthole sampling usually presents poor sampling precision, and the inconstant sampling bias caused by particle size and density segregation is an even more serious problem, generally precluding representativeness. One of the main causes of this bias is a highly varying loss of fines, which can lead to both under-and over-estimation of grade depending on the ore type and the gangue. This study validates a new, modified sectorial sampler, designed to reduce the loss of fines and thereby increase sampling accuracy for narrow-diameter blasthole sampling. First results show a significantly improved estimation of gold grade as well as the minimization of the loss of fines.
\end{abstract}

Keywords: Sampling, reconciliation, gold, stationary sectorial sampler, blasthole sampling. 


\section{Introdução}

A crescente complexidade das operações mineiras, que trabalham com teores cada vez mais baixos, requer, mais do que nunca, amostras suficientemente acuradas e precisas, visando a um melhor controle e a uma maior otimização de seus processos. Os métodos de amostragem - tais como sondagem, amostragem de furos de desmonte (pequeno e grande diâmetro), amostragem de canal, amostragem de materiais particulados, etc. - são diversos e devem ser selecionados de acordo com o tipo de depósito e, ainda, de acordo com a finalidade das informações. Cada método gera um erro total de amostragem, que deve ser quantificado, a fim de se avaliar a adequação do método, no que diz respeito aos objetivos e à qualidade desejada (precisão, acurácia, esforço de trabalho).

Sabe-se que uma amostra deve representar uma unidade ou um volume de material. A metodologia de amostragem é considerada correta e imparcial somente se todas as partículas, na unidade, têm, exatamente, a mesma probabilidade de seleção para compor a amostra aleatória. Estudos demonstram que mesmo pequenas melhorias nos processos de amostragem resultam em benefícios significativos para as operações mineiras. Dessa maneira, equipamentos de amostragem corretos, procedimentos operacionais corretos e protocolos de amostragem otimizados são de essencial importância para uma amostragem bem-sucedida, garantindo-se a seleção de amostras representativas, de acordo com os princípios da Teoria da Amostragem.

A heterogeneidade constitucional também é um fator importante a ser considerado, quando do planejamento de uma campanha de amostragem, uma vez que a heterogeneidade, por si só, e especialmente quando se trata de metais preciosos, pode gerar erros elevadíssimos, mesmo quando o processo de amostragem é realizado de maneira correta.

Esse trabalho apresenta os resultados dos testes de validação de um novo amostrador, para furos de desmonte de pequeno diâmetro, em termos de reconciliação entre mina e usina. Visando a quantificar a perda de finos, um problema comum da amostragem de furos de desmonte e que pode comprometer as estimativas de teores dos modelos de blocos (Chieregati et al., 2008), o procedimento de amostragem, utilizando o novo amostrador foi, também, comparado com outros dois procedimentos de amostragem de furos de desmonte: (i) amostragem utilizando um tambor e (ii) amostragem utilizando uma lona.

\section{Materiais e métodos}

Amostras, para controle de teor, ou para o planejamento de curto prazo, muitas vezes resultam de campanhas de amostragem de furos de desmonte. Tais amostras, geralmente, apresentam uma baixa recuperação, devido à segregação de partículas e, em consequência, não são consideradas representativas da amostra total (Schofield, 2001; Pitard, 2008, 2009). Uma das principais causas desse enviesamento é a perda de finos, que pode levar a uma sub ou a uma superestimativa do teor, dependendo do tipo de minério e da composição da ganga (Snowden, 1993).
Uma amostra é considerada correta, somente quando todos os fragmentos do lote a ser amostrado têm a mesma probabilidade de seleção. Uma amostra pode ser qualificada como representativa, somente quando for correta (acurada) e suficientemente reproduzível (precisa), ou seja, uma amostra representativa deve, incondicionalmente, ser imparcial e apresentar uma variância suficientemente baixa. Na prática, procedimentos corretos de amostragem não são necessariamente simples de se realizar, especialmente para materiais heterogêneos. No entanto, como o risco de enviesamento nunca é aceitável, deve-se rejeitar qualquer procedimento ou equipamento de amostragem que não cumprir esses requisitos, devido à falta de garantia da representatividade da amostra gerada.

O presente estudo foi realizado na Mineração Serra Grande, uma mina de ouro da Kinross e AngloGold Ashanti, em Crixás, e constou de duas campanhas de amostragem, na mina a céu aberto, visando a verificar a representatividade das amostras geradas pelo novo amostrador de furos de desmonte, bem como a quantificar a perda de finos por três diferentes procedimentos de amostragem.

\section{Amostrador setorial estacionário com cúpula}

Com o objetivo de minimizar os erros de amostragem associados à amostragem de furos de desmonte, especialmente os erros de delimitação do incremento (IDE) e de extração do incremento (IEE), Chieregati (2007) propôs um novo equipamento de amostragem chamado "amostrador setorial estacionário com cúpula”, uma adaptação do amostrador setorial estacionário proposto por Pitard (1993). A Figura 1 ilustra o amostrador modificado, o qual deve ser posicionado ao redor do furo de desmonte a ser perfurado.

Os recipientes setoriais têm a forma de pizza e devem ser facilmente removi- dos da armação. Os lados dos recipientes devem ser radiais, com relação ao centro do furo, de modo a estarem de acordo com os princípios da Teoria da Amostragem. Os recipientes devem, também, ser fundos o suficiente para não transbordar antes do final da perfuração (Pitard, 1993). A nova cúpula semi-esférica é feita de material acrílico e respeita as condições de seleção de amostras corretas. Essa modificação minimiza o risco de contaminação e, também, os erros introduzidos por amostragem manual. $\mathrm{Na}$ parte superior da cúpula, foi inserida uma borracha de vedação (Figura 3), de forma a minimizar os erros causados pela perda de finos. O amostrador setorial é encaixado na lança da perfuratriz e gera dois incrementos ou duas amostras, pesando entre $2 \mathrm{~kg}$ e $3 \mathrm{~kg}$ cada. Conforme mostra a Figura 2, os recipientes setoriais são posicionados em dois quadrantes do amostrador, cada um coletando um incremento representado por um setor da amostra total. Portanto o amostrador setorial funciona, também, como um quarteador.

Para verificar a adequação do novo amostrador à estimativa do teor médio do minério, uma campanha de amostragem foi realizada no bloco I5A da $\mathrm{Mi}$ neração Serra Grande. Para isso, 48 fu- 


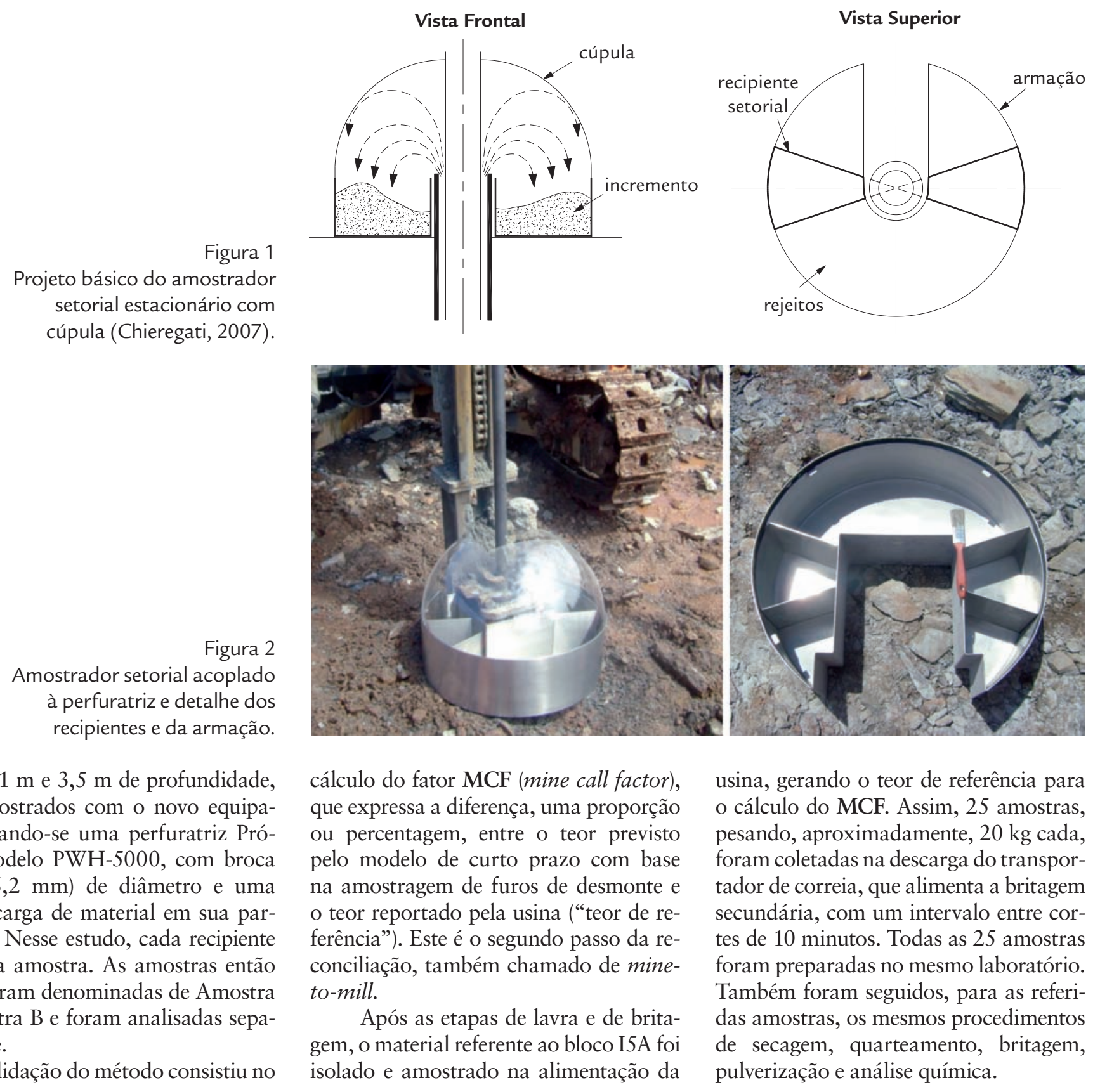

ros, entre $1 \mathrm{~m}$ e 3,5 $\mathrm{m}$ de profundidade, foram amostrados com o novo equipamento, usando-se uma perfuratriz PróEletro, modelo PWH-5000, com broca de 3" $(76,2 \mathrm{~mm})$ de diâmetro e uma única descarga de material em sua parte frontal. Nesse estudo, cada recipiente gerou uma amostra. As amostras então geradas foram denominadas de Amostra A e Amostra B e foram analisadas separadamente.

A validação do método consistiu no cálculo do fator MCF (mine call factor), que expressa a diferença, uma proporção ou percentagem, entre o teor previsto pelo modelo de curto prazo com base na amostragem de furos de desmonte e o teor reportado pela usina ("teor de referência”). Este é o segundo passo da reconciliação, também chamado de mineisolado e amostrado na alimentação da usina, gerando o teor de referência para o cálculo do MCF. Assim, 25 amostras, pesando, aproximadamente, $20 \mathrm{~kg}$ cada, foram coletadas na descarga do transportador de correia, que alimenta a britagem secundária, com um intervalo entre cortes de 10 minutos. Todas as 25 amostras foram preparadas no mesmo laboratório. Também foram seguidos, para as referidas amostras, os mesmos procedimentos pulverização e análise química.

\section{Comparação de diferentes procedimentos de amostragem de furos de desmonte}

Uma campanha de amostragem concomitante foi conduzida na Mineração Serra Grande. O objetivo foi o de quantificar a recuperação de finos do amostrador setorial, em relação aos dois procedimentos de amostragem de furos de desmonte empregados anteriormente na mina - amostragem usando uma lona e usando um tambor (Figura 3).

Foram realizados seis furos, dois por método de amostragem, e a com- paração entre os métodos baseou-se na distribuição média de tamanhos de partícula das amostras obtidas.

Visando a minimizar a perda de finos e a evitar a contaminação da amostra, as seguintes medidas foram tomadas: (i) quatro pessoas realizaram a amostragem com a lona, cujas extremidades foram mantidas elevadas, de modo a minimizar o efeito do vento; (ii) três pessoas realizaram a amostra- gem com o tambor, o qual foi envolvido com a lona para minimizar a perda de finos; (iii) duas pessoas realizaram a amostragem com o amostrador setorial, sendo a cúpula coberta por uma borracha de vedação, também para minimizar a perda de finos. Cada ciclo de amostragem com a lona durou, em média, sete minutos, com o tambor, oito minutos e com o amostrador setorial quatro minutos.

\section{Resultados}

De acordo com Pitard (2008, 2009), a amostragem de furos de desmonte, para controle de qualidade, adquiriu uma péssima reputação, nos últimos 50 anos, devido às diversas fontes de enviesamento introduzidas por essa operação e à consequente dificuldade de se documentar uma amostragem representativa. Além disto, alega-se que a amostragem 

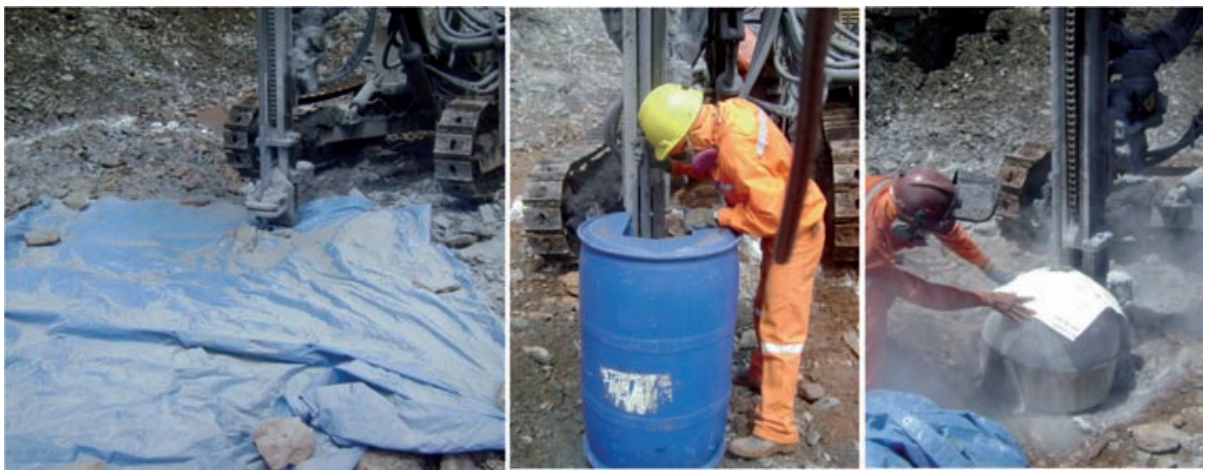

de furos de desmonte, quando realizada adequadamente, reduz a produtividade da perfuração. Esse cenário pode ser melhorado se levarmos em consideração os erros de delimitação, extração e ponderação do incremento (IDE, IEE e IWE), bem como o fenômeno da segregação, e se usarmos amostradores projetados de acordo com a Teoria da Amostragem. Comprovada a capacidade de um procedimento ou equipamento de amostragem de gerar amostras representativas, a avaliação final da empresa deveria basear-se nos benefícios que esse procedimento tra-

\section{Validação do amostrador setorial estacionário com cúpula}

A Tabela 1 apresenta os valores de teor de ouro, para as amostras A e B, bem como os erros absolutos e relativos. Deve-se observar que as amostras A e B referem-se aos incrementos dos dois recipientes em quadrantes opostos do amostrador setorial estacionário e, portanto, os resultados desse procedimento visam a validar a operação do amostrador seto- rial com cúpula.

Os resultados mostram que a acurácia do processo de amostragem é boa $(\mathbf{m}=0,067)$ e, portanto, que não há enviesamento significativo entre a Amostra A e a Amostra B (média do erro relativo $=2,45 \%$ ). Isto sugere que os recipientes do amostrador setorial geram duas amostras equivalentes. Por outro lado, a
Figura 3

Diferentes procedimentos de amostragem: lona, tambor e amostrador setorial.

ria para a operação como um todo.

Como apresentado nos itens a seguir, os resultados do presente trabalho mostram uma melhoria significativa na representatividade da amostra, demonstrada por um excelente valor de reconciliação e pela minimização da perda de finos.

\begin{tabular}{|c|c|c|c|c|c|c|c|c|c|}
\hline $\begin{array}{c}\text { Número } \\
\text { do } \\
\text { furo }\end{array}$ & $\begin{array}{c}\text { Teor } \\
\text { Amostra A } \\
(\mathrm{g} / \mathrm{t})\end{array}$ & $\begin{array}{c}\text { Teor } \\
\text { Amostra B } \\
(\mathrm{g} / \mathrm{t})\end{array}$ & $\begin{array}{c}\text { Erro } \\
\text { absoluto }\end{array}$ & $\begin{array}{c}\text { Erro } \\
\text { relativo } \\
(\%)\end{array}$ & $\begin{array}{c}\text { Número } \\
\text { do } \\
\text { furo }\end{array}$ & $\begin{array}{c}\text { Teor } \\
\text { Amostra A } \\
(\mathrm{g} / \mathrm{t})\end{array}$ & $\begin{array}{c}\text { Teor } \\
\text { Amostra B } \\
(\mathrm{g} / \mathrm{t})\end{array}$ & $\begin{array}{c}\text { Erro } \\
\text { absoluto }\end{array}$ & $\begin{array}{c}\text { Erro } \\
\text { relativo } \\
(\%)\end{array}$ \\
\hline 1 & 0,73 & 2,27 & $-1,54$ & $-67,84 \%$ & 25 & 5,03 & 5,10 & $-0,07$ & $-1,37 \%$ \\
\hline 2 & 0,03 & 0,03 & 0,00 & $0,00 \%$ & 26 & 2,33 & 2,50 & $-0,17$ & $-6,80 \%$ \\
\hline 3 & 1,33 & 1,07 & 0,26 & $24,30 \%$ & 27 & 1,17 & 1,33 & $-0,16$ & $-12,03 \%$ \\
\hline 4 & 3,13 & 4,77 & $-1,64$ & $-34,38 \%$ & 28 & 5,43 & 3,83 & 1,60 & $41,78 \%$ \\
\hline 5 & 1,10 & 2,37 & $-1,27$ & $-53,59 \%$ & 29 & 7,20 & 6,60 & 0,60 & $9,09 \%$ \\
\hline 6 & 3,83 & 2,17 & 1,66 & $76,50 \%$ & 30 & 1,13 & 1,23 & $-0,10$ & $-8,13 \%$ \\
\hline 7 & 7,80 & 7,97 & $-0,17$ & $-2,13 \%$ & 31 & 1,10 & 8,83 & $-7,73$ & $-87,54 \%$ \\
\hline 8 & 1,43 & 2,57 & $-1,14$ & $-44,36 \%$ & 32 & 3,87 & 4,40 & $-0,53$ & $-12,05 \%$ \\
\hline 9 & 14,67 & 14,03 & 0,64 & $4,56 \%$ & 33 & 13,90 & 16,67 & $-2,77$ & $-16,62 \%$ \\
\hline 10 & 6,90 & 5,17 & 1,73 & $33,46 \%$ & 34 & 7,60 & 7,87 & $-0,27$ & $-3,43 \%$ \\
\hline 11 & 5,80 & 6,00 & $-0,20$ & $-3,33 \%$ & 35 & 8,43 & 8,30 & 0,13 & $1,57 \%$ \\
\hline 12 & 1,50 & 1,57 & $-0,07$ & $-4,46 \%$ & 36 & 8,07 & 7,00 & 1,07 & $15,29 \%$ \\
\hline 13 & 3,33 & 2,93 & 0,40 & $13,65 \%$ & 37 & 5,37 & 5,60 & $-0,23$ & $-4,11 \%$ \\
\hline 14 & 5,33 & 4,43 & 0,90 & $20,32 \%$ & 38 & 11,77 & 7,07 & 4,70 & $66,48 \%$ \\
\hline 15 & 9,47 & 8,30 & 1,17 & $14,10 \%$ & 39 & 5,07 & 5,93 & $-0,86$ & $-14,50 \%$ \\
\hline 16 & 9,77 & 11,90 & $-2,13$ & $-17,90 \%$ & 40 & 3,57 & 2,77 & 0,80 & $28,88 \%$ \\
\hline 17 & 0,67 & 1,27 & $-0,60$ & $-47,24 \%$ & 41 & 0,93 & 0,83 & 0,10 & $12,05 \%$ \\
\hline $18^{*}$ & & *amostra p & perdida & & 42 & 12,30 & 7,27 & 5,03 & $69,19 \%$ \\
\hline 19 & 6,50 & 5,80 & 0,70 & $12,07 \%$ & 43 & 4,20 & 3,23 & 0,97 & $30,03 \%$ \\
\hline 20 & 7,67 & 9,17 & $-1,50$ & $-16,36 \%$ & 44 & 1,53 & 1,27 & 0,26 & $20,47 \%$ \\
\hline 21 & 9,50 & 5,93 & 3,57 & $60,20 \%$ & 45 & 2,67 & 2,40 & 0,27 & $11,25 \%$ \\
\hline 22 & 5,90 & 6,37 & $-0,47$ & $-7,38 \%$ & 46 & 7,50 & 6,47 & 1,03 & $15,92 \%$ \\
\hline 23 & 8,83 & 9,50 & $-0,67$ & $-7,05 \%$ & 47 & 5,00 & 3,97 & 1,03 & $25,94 \%$ \\
\hline 24 & 6,17 & 7,03 & $-0,86$ & $-12,23 \%$ & 48 & 3,83 & 4,13 & $-0,30$ & $-7,26 \%$ \\
\hline \multicolumn{6}{|r|}{ Média } & 5,327 & 5,260 & 0,067 & $2,45 \%$ \\
\hline \multicolumn{6}{|c|}{ Desvio padrão } & 3,677 & 3,500 & 1,878 & $32,6 \%$ \\
\hline
\end{tabular}

reprodutibilidade ou precisão é baixa $(\mathbf{s}=$ $\pm 32,6 \%$ relativo), o que é um fenômeno comum, para minérios de ouro e ambientes com efeito pepita elevado.

Em se tratando de amostragem de ouro, não é raro classificar, de forma incorreta, minério e estéril, devido à baixa precisão da amostragem. No entanto, existem métodos para analisar se as es-

Tabela 1

Resultados da campanha de amostragem com o novo amostrador setorial. 
timativas estão dentro de limites aceitáveis, como, por exemplo, a "elipse de precisão”. Não será incluída, nesse trabalho, uma discussão sobre o efeito pepita e a elipse de precisão (para mais informações ver Pitard, 2009), mas as questões referentes à heterogeneidade do depósito devem ser levadas em consideração, ao se analisar a precisão de qualquer campanha de amostragem.

O procedimento de amostragem, para o cálculo de reconciliação, foi realizado na alimentação da usina e gerou
25 amostras de cortes a cada 10 minutos, seguindo os princípios da Teoria da Amostragem. O teor médio resultante da amostragem, na usina, é, aqui, considerado como o "teor de referência", para o cálculo do MCF, pois é o valor mais confiável obtido para o teor médio do bloco. O MCF é calculado, dividindo-se o teor médio de ouro na alimentação da usina $(5,172 \mathrm{~g} / \mathrm{t})$ pelo teor médio de ouro gerado pelo amostrador setorial $\left(\right.$ média $\left._{\text {AmostraA/AmostraB }}=5,294 \mathrm{~g} / \mathrm{t}\right)$. Nesse caso, $\mathrm{MCF}=97,7 \%$, o que é excelente.
O MCF mostra um erro de estimativa de apenas $2,3 \%$, validando o amostrador setorial estacionário com cúpula como um equipamento de amostragem adequado para a estimativa de curto prazo.

Os autores recomendam a realização de novos trabalhos, tanto nesta como em outras operações mineiras, com o objetivo de estudar a eficiência do novo amostrador setorial, para um campo mais amplo de tipos de mineralização e de processos minerais.

\section{Estimativa de recuperação de finos por diferentes procedimentos de amostragem}

A Figura 4 mostra a distribuição média de tamanhos de partícula, para os três procedimentos de amostragem investigados.

A Figura 4 mostra uma maior recuperação de material fino pelo amostrador setorial com cúpula (31,3\%). A segunda maior recuperação de material fino deu-se pela amostragem com tambor $(22,8 \%)$. Finalmente, a menor recuperação de material fino deu-se pela amostragem com a lona (16,6\%). A fração granulométrica maior apresentou uma tendência oposta e as frações intermediárias apresentaram percentagens semelhantes de material retido.
Os resultados sugerem que, entre os três procedimentos de amostragem analisados, o amostrador setorial com cúpula é o que apresenta a menor perda de finos e, consequentemente, pode ser considerado o procedimento mais confiável para este tipo de amostragem.
Figura 4

Média das distribuições de tamanho, para os três procedimentos de amostragem.

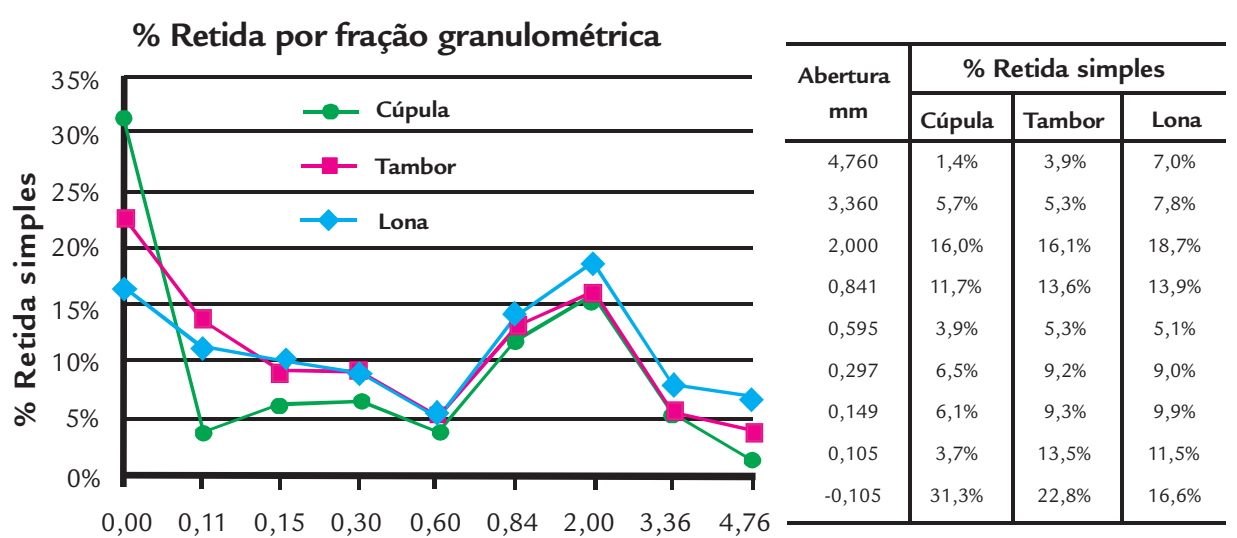

Abertura nominal (mm)

\section{Discussão}

Problemas de reconciliação, devido a erros de amostragem, não são raros na indústria do ouro, principalmente devido à heterogeneidade elevada da mineralização e aos valores elevados de efeito pepita, que são características comuns a esses ambientes. Portanto a minimização dos erros de amostragem é imprescindível, quando a empresa faz uso das ferramentas de reconciliação, para controlar e otimizar seus processos. Os resultados do presente trabalho permitem fazer as seguintes considerações:

- O baixo valor da média do erro de seleção da amostra $(0,067)$ mostra que os setores opostos do amostrador setorial são imparciais. Entretanto a reprodutibilidade associada é baixa $( \pm 32,6 \%)$. Isto sugere que a amostra gerada pelo amostrador setorial é acurada, mas não precisa. A baixa precisão é um fenômeno comum em ambientes com efeito pepita elevado e com elevada heterogeneidade. Em se tratando de uma mineralização com presença de ouro grosso, o elevado efeito pepita associado à jazida estudada exige cuidado no tratamento dos dados e na definição do número mínimo de amostras necessário para a estimativa do teor de um bloco ou polígono de lavra. Uma recomendação seria combinar ambas as amostras A e B, formando uma única amostra a ser enviada ao laboratório. Recomenda-se, também, usar a técnica de screen fire assay, em vez da técnica padrão de fire assay, para a análise do teor de ouro. A técnica de screen fire assay minimiza a influência do efeito pepita na quantificação dos teores, visto que, por meio de peneiramento e de análise individual das frações grossa e fina, evita que a presença de fragmentos de ouro grosso na amostra analítica mascare o teor real da amostra original. Portanto esse resultado deve ser fundamentado por meio de estudos paralelos, abrangendo outros tipos de mineralizações de ouro, antes que generalizações possam ser feitas.

- O alto valor do MCF sugere uma boa previsibilidade do modelo de curto prazo com base nos resultados do novo amostrador setorial.

- A recuperação, significativamente maior de material fino, pelo novo amostrador setorial, confirma a mini- 
mização do erro de amostragem devido à perda de finos.

\section{Conclusões}

Mesmo com baixa precisão, melhorias nos resultados de reconciliação foram demonstradas na Mineração Serra Grande, sugerindo que o novo amostrador setorial estacionário com cúpula pode trazer benefícios expressivos para a indústria mineira. $\mathrm{O}$ método de amostragem, utilizando o amostrador setorial, apresenta resultados muito satisfatórios, para fins de reconciliação. Também apresenta custos operacionais mais baixos, mínima redução de produtividade e maior acurácia das estimativas, se comparado aos métodos tradicionais usados em minas a céu aberto.

\section{Agradecimentos}

O presente trabalho foi realizado com apoio do CNPq, Conselho $\mathrm{Na}$ cional de Desenvolvimento Científico
- O novo amostrador setorial não reduz, significativamente, a produtivi- dade das perfuratrizes em relação à rotina-padrão de trabalho.

\section{Referências bibliográficas}

CHIEREGATI, A.C. Amostradorsetorial estacionário com cúpula. Patente brasileira, n. PI0706010-6A2, São Paulo: INPI, 5 out. 2007.

CHIEREGATI, A.C., DELBONI JR., H., COSTA, J.F.C.L., CARNEIRO, F.B. Reconciliação pró-ativa em empreendimentos mineiros. REM - Revista Escola de Minas, v. 61, p. 297-302, 2008.

PITARD, F. F. Pierre Gy's sampling theory and sampling practice: heterogeneity, sampling correctness, and statistical process control. 2 ed. Boca Raton: CRC Press, 1993. 488p.

PITARD, F.F. Blasthole sampling for grade control: the many problems and solutions. In: SAMPLING 2008. Perth. Anais... Melbourne: AusIMM, 2008. p. 27-28.

PITARD, F.F. Pierre Gy's theory of sampling and C.O. Ingamell's Poisson process approach. Esbjerg: Aalborg University, 2009.309p. (Tese de Doutorado).

SCHOFIELD, N. A. The myth of mine reconciliation. In: Mineral resource and ore reserve estimation: the AusIMM guide to good practice. EDWARDS, A. C. (Ed.). Melbourne: AusIMM, 2001. p. 601-610.

SNOWDEN, V. Comparative 3-D resource modeling approaches at Macraes deposit in New Zealand and their reconciliation with production. In: Applications of Computers in the Mineral Industry. New South Wales: University of Wollongong, 1993. p. 42-45.

Artigo recebido em 14 de junho de 2011 . Aprovado em 07 de novembro de 2011. 